\title{
THIN-LAYER CHROMATOGRAPHY OF SOME PREGNENES AND PREGNADIENES
}

\author{
LOTFY A. R. SALLAM, ABDEL MONEM H. EL-REFAI, \\ AND NADIA NAIM \\ Microbiological Chemistry Research Laboratory, \\ National Research Center, Dokki, Cairo, Egypt
}

(Received November 29, 1973)

\begin{abstract}
The resolution of different steroids on a thin-layer plate with a large number of solvent systems was investigated. These steroids are of the pregnene models differing in the number and position of the double bond, and ketone and hydroxyl groups. The mobility of these steroids on the plate with the most suitable solvent systems ( 9 different systems) was described. The characteristic colours of the tested steroids upon using different colour reagents are also given. The results of these studies may be of importance to workers interested in the field of microbiological transformation of steroids; especially those concerned with the study of dehydrogenation reactions.
\end{abstract}

The recent development in the field of the microbiological transformation of steroids stimulated some workers to develop a useful technique for the improvement of the method for detection of the variety of transformation products by the action of microorganisms on steroids.

Most of the earlier methods described for the identification and determination of the transformation products of steroidal substances were those in which paper chromatographic techniques were adopted. All of these methods were modification of ZAFFARONI's method (1). However, in recent years, the thin-layer chromatographic technique proved its advantages over paper partition chromatography as a rapid tool for the identification of mixtures of steroidal compounds (25). More recently, Sallam et al. (6) described the resolution of 30 different C-21, C-19, and C-18 steroids by various solvent systems on silica gel $\mathrm{G}$ chromatoplates. On the other hand, the resolution of the triols of pregnane and pregnene models was achieved with relatively little success. The poor separation of such steroids represented one of the important practical problems in studying the microbiological transformation of cortisol to prednisolone. Therefore, it was thought of interest to study the resolution of the latter two compounds and intimately related 
derivatives usually formed as bioconversion metabolites of cortisol and similar steroids.

\section{EXPERIMENTAL}

Preparation of the plates. The chromatoplates were prepared by slurring the adsorbent silica gel G (Merck) in distilled water. For five $20 \times 20 \mathrm{~cm}$ plates, $30 \mathrm{~g}$ of the adsorbent was used in $60 \mathrm{ml}$ distilled water and the slurry was applied with a desaga instrument. In some experimental series, silica gel $\mathrm{G}$ impregnated with silver nitrate, aluminium chloride, or boric acid was used. The plates were dried in an oven at $110^{\circ}$ for $1 \mathrm{hr}$, left to cool, and stored in a desiccator.

Development. For the separation of the test steroids, different solvent systems were suggested. Modifications was made on each of the proposed systems either by changing the proportion of one of its components (mostly the more polar one)

Table 1. Composition and modification of different solvent systems used for the resolution of tested steroids.

\begin{tabular}{|c|c|c|}
\hline System & $\begin{array}{l}\text { Changed } \\
\text { component }\end{array}$ & Proportions \\
\hline $\begin{array}{l}\text { Cyclohexane: chloroform: acetic acid } \\
\quad(8: 1: 1 ; \mathrm{v} / \mathrm{v})\end{array}$ & Acetic acid & $1.5,2,3,4$ \\
\hline $\begin{array}{l}\text { Cyclohexane: acetone: chloroform } \\
\quad(10: 5: 5 ; \mathrm{v} / \mathrm{v})\end{array}$ & Chloroform & $6,8,12$ \\
\hline $\begin{array}{l}\text { Cyclohexane: acetone: chloroform: acetic acid } \\
\quad(50: 25: 30: 0.03 ; \mathrm{v} / \mathrm{v})\end{array}$ & Acetic acid & $\begin{array}{l}0.06,0.09,0.12 \\
0.18,0.20\end{array}$ \\
\hline $\begin{array}{l}\text { Benzene: ethyl acetate: acetone } \\
\quad(20: 5: 1 ; \mathrm{v} / \mathrm{v})\end{array}$ & Acetone & $1,2,3,4,5$ \\
\hline $\begin{array}{l}\text { Benzene: ethyl acetate: acetone: acetic acid } \\
\quad(20: 5: 5: 1 ; \mathrm{v} / \mathrm{v})\end{array}$ & Acetic acid & $2,3,4,5,6$ \\
\hline $\begin{array}{l}\text { Benzene: chloroform: methanol } \\
\quad(60: 40: 2 ; \mathrm{v} / \mathrm{v})\end{array}$ & Methanol & $3,5,7,10$ \\
\hline Chloroform: methanol $(90: 3 ; \mathrm{v} / \mathrm{v})$ & Methanol & $5,10,15$ \\
\hline $\begin{array}{l}\text { Chloroform: methanol: ammonia } \\
\quad(40: 5: 0.1 ; \mathrm{v} / \mathrm{v})\end{array}$ & Ammonia & $0.2,0.3,0.5$ \\
\hline Chloroform: acetic acid $(90: 5 ; \mathrm{v} / \mathrm{v})$ & Acetic acid & 7,10 \\
\hline Chloroform: acetone $(40: 5 ; \mathrm{v} / \mathrm{v})$ & Acetone & $7,8,10$ \\
\hline $\begin{array}{l}\text { Chloroform: acetone: ethanol } \\
\quad(40: 10: 0.1 ; \mathrm{v} / \mathrm{v})\end{array}$ & Ethanol & $0.2,0.3,0.4,0.7$ \\
\hline $\begin{array}{l}\text { Toluene: ethyl acetate: acetic acid } \\
\qquad(12: 4: 0.25 ; \mathrm{v} / \mathrm{v})\end{array}$ & Acetic acid & $0.5,1,1.5$ \\
\hline $\begin{array}{l}\text { Toluene: chloroform: methanol } \\
\qquad(10: 10: 1 ; \mathrm{v} / \mathrm{v})\end{array}$ & Methanol & $2,3,4,5$ \\
\hline $\begin{array}{l}\text { Benzene: chloroform: ethanol } \\
\quad(10: 40: 5 ; \mathrm{v} / \mathrm{v})\end{array}$ & Ethanol & $6,7,9$ \\
\hline $\begin{array}{l}\text { Benzene: chloroform: methanol } \\
\quad(6: 2: 2 ; \mathrm{v} / \mathrm{v})\end{array}$ & Methanol & 4,5 \\
\hline
\end{tabular}


or through addition of another new constituent. These systems and their modifcations are presented in Table 1.

Detection. For detection of the spots, the following colour reagents were used: (a) Chlorosulphonic acid: acetic acid (3: 1; v/v), (b) vaniline: $\mathrm{HClO}_{4} ; 1 \%$ vaniline solution in $10 \% \mathrm{HClO}_{4}$, (c) Liebermann-Burchard reaction (7); acetic anhydride: conc. $\mathrm{H}_{2} \mathrm{SO}_{4}$ : absolute ethanol $(5: 5: 50 ; \mathrm{v} / \mathrm{v})$. A mixture of acetic acid and $\mathrm{H}_{2} \mathrm{SO}_{4}$ is added to ethanol slowly while cooling. (d) Absolute ethanol: conc. $\mathrm{H}_{2} \mathrm{SO}_{4}(55: 44 ; \mathrm{v} / \mathrm{v}), \mathrm{H}_{2} \mathrm{SO}_{4}$ is added slowly dropwise to ice-cold ethanol with stirring.

After spraying with either of the colour reagents, the plates were heated at $110^{\circ}$ for $5 \mathrm{~min}$ whereby the colour of the spots were characterized in the day light as well as under UV rays.

Steroid samples used were: prednisone, 20 $\beta$-hydroxyprednisolone, cortisol, epicortisol, prednisolone, epiprednisolone, 20 $\beta$-hydroxyepiprednisolone, $20 \beta$ hydroxycortisol, 20 $\beta$-hydroxyprednisolone.

\section{RESULTS AND DISCUSSION}

Of the solvent systems and their modifications listed in Table 1, the following ones proved to be the most suitable formulations for the resolution of the closely related steroids tested.

I: Cyclohexane: acetone: chloroform: acetic acid (50: $25: 30: 0.20 ; \mathrm{v} / \mathrm{v})$.

II: Benzene: ethyl acetate: acetone: acetic acid (20: $5: 5: 0.15 ; \mathrm{v} / \mathrm{v})$.

III: Chloroform: acetone: ethanol (40:10:0.7; v/v).

IV: Toluene: ethyl acetate: acetic acid $(24: 8: 6 ; \mathrm{v} / \mathrm{v})$.

V: Cyclohexane: chloroform: acetic acid (40:10:10; v/v).

VI: Chloroform: cylohexane: isopropanol $(50: 20: 20 ; \mathrm{v} / \mathrm{v})$.

VII: Toluene: methanol: chloroform $(10: 2: 10 ; \mathrm{v} / \mathrm{v})$.

Table 2. Mobilities of the tested steroids with selected solvent systems.

\begin{tabular}{|c|c|c|c|c|c|c|c|}
\hline \multirow{2}{*}{ Compounds } & \multicolumn{7}{|c|}{$R f \times 100$ with solvent systems } \\
\hline & I & II & III & IV & V & VI & VII \\
\hline 1. Prednisone & 26 & 31 & 50 & 30 & 20 & 70 & 47 \\
\hline 2. $20 \beta$-Hydroxyprednisone & 24 & 18 & 48 & 25 & 12 & 50 & 22 \\
\hline 3. Cortisol & 16 & 15 & 40 & 22 & 8 & 44 & 20 \\
\hline 4. Epicortisol & 10 & 13 & 30 & 15 & 5 & 33 & 15 \\
\hline 5. Prednisolone & 14 & 13 & 38 & 20 & 6 & 41 & 17 \\
\hline 6. Epiprednisolone & 7 & 8 & 17 & 14 & 4 & 25 & 12 \\
\hline 7. $20 \beta$-Hydroxycortisol & 4 & 4 & 6 & 11 & 3 & 20 & 10 \\
\hline 8. $20 \beta$-Hydroxyprednisolone & 3 & 3 & 4 & 7 & 3 & 15 & 8 \\
\hline 9. $20 \beta$-Hydroxyepiprednisolone & 0 & 0 & 0 & 0 & 0 & 0 & 0 \\
\hline
\end{tabular}


The thin-layer chromatograms of the tested steroids with these different solvent systems are given in Table 2 . The steroids used are pregnane models differing in the number and position of the double bonds, and ketonic and hydroxyl groups. They may be broadly classified on the basis of their hydroxyl content to dihydroxy, trihydroxy, and tetrahydroxy compounds.

In general, the mobilities of these compounds differ with the solvent used. Thus, while higher $R f$ values for the steroids tested are recorded with the solvent systems III and VI, lower migration rates are obtained with other systems; I, II, IV, and VII. Since the relative strengths of the polar constituents of the different systems used are nearly the same; $0.25(8)$, it may be claimed that the proportion of the polar components in the solvent mixtures is the decisive factor affecting the migration rates of the steroids used. This concept may have a support if the composition of the different solvents is considered. Thus solvent VI, with which higher migration rates are obtained, contains chloroform 2.5 times that of cyclohexane and isopropanol. On the other hand, with system $\mathrm{V}$ which supported lower $R f$ values, the amount of cyclohexane (nonpolar component) is 4 times that of other polar constituents. The same principle may be held to the distribution of the compounds with other systems.

As far as the separation of the tested steroids is concerned, the dihydroxy compounds; prednisone (compound 1) migrated more rapidly than other compounds and had higher $R f$ values with all solvent systems used, and thus it can be easily separated from other steroids.

The triols (compounds 2-6) are fairly resolved with all the solvent systems used. 20 $\beta$-Hydroxyprednisone migrates faster than other compounds. Although $20 \beta$-hydroxyprednisone contains a conjugated diene system and cotisol lacks such

Table 3. Different colours of individual steroids tested.

\begin{tabular}{|c|c|c|c|c|c|c|c|}
\hline \multirow{3}{*}{ Compounds } & \multicolumn{7}{|c|}{ Colour reagents } \\
\hline & \multirow{2}{*}{$\begin{array}{c}\text { Chloro- } \\
\text { sulphonic } \\
\text { D.L.* U.V.* }\end{array}$} & \multicolumn{2}{|c|}{$\begin{array}{l}\text { Libermann- } \\
\text { Burchard }\end{array}$} & \multicolumn{2}{|c|}{ Vaniline } & \multicolumn{2}{|c|}{$\begin{array}{l}\mathrm{H}_{2} \mathrm{SO}_{4-}^{-} \\
\text {ethanol }\end{array}$} \\
\hline & & D.L. & U.V. & D.L. & U.V. & D.L. & U.V. \\
\hline $\begin{array}{l}\text { Prednisone } \\
\text { 20 } \beta \text {-Hydroxyprednisone }\end{array}$ & $\begin{array}{l}\text { d.br. } \\
\text { ol. gr. }\end{array}$ & $\begin{array}{l}\text { br. } \\
\text { bu. }\end{array}$ & $\begin{array}{l}\text { d.br. } \\
\text { v. }\end{array}$ & $\begin{array}{l}\text { d.v. } \\
\text { f.v. }\end{array}$ & $\begin{array}{l}\text { d.v. } \\
\text { g. }\end{array}$ & $\begin{array}{l}\text { f.v. } \\
\text { bu. }\end{array}$ & $\begin{array}{l}\text { s.bl. } \\
\text { ro. }\end{array}$ \\
\hline Cortisol & p.br. d.br. & p.br. & d.br. & g. & d.y. & ol. & gy. \\
\hline Epicortisol & p.br. y. & p.br. & y. & - & - & - & - \\
\hline Prednisolone & d.br. & br. & d.br. & gr. & br. & brd. & brd. \\
\hline Epiprednisolone & brd. s.bl. & or. & v. & bu.v. & brd. & v. & s.bl. \\
\hline $20 \beta$-Hydroxycortisol & brd. gy. & ol. & $\operatorname{lm}$. & d.v. & d.v. & 一 & - \\
\hline $20 \beta$-Hydroxyprednisolone & rv. & - & - & rv. & rv. & ro. & ro. \\
\hline $20 \beta$-Hydroxyepiprednisolone & br. & b. & $\mathrm{y}$. & br. & br. & f.br. & ol. \\
\hline
\end{tabular}

Abbreviations: br., brown; d., deep; v., violet; f., faint; s.bl., sky blue; or., orange; ol., olive; gr., green; bu., bluish; g., grey; ro., rose; gy., golden yellow; y., yellow; brd., brick red; rv., reddish violet; b., buff; p., pale; lm., lemon.

*D.L., day light; U.V., ultraviolet ray. 
structure, the latter compound appears to be more polar. This may be attributed to the effect of the axial $11 \beta$-hydroxyl group which confers more polarity than both the conjugated system and $20 \beta$-hydroxyl group in $20 \beta$-hydroxyprednisone. Epicortisol, the 11- epimer of cortisol, is more polar than cortisol due to the effect of the equatorial $11 \alpha$-hydroxyl group. The same phenomenon is observed with prednisolone and epiprednisolone (compounds 5 and 6); compound 6 is more polar and has lower $R f$ value with all the solvent systems used.

The tetrols (compounds 7-9) are easily separated from other steroids. 20 $\beta$ Hydroxyepiprednisolone remained at the origin of the plate with all the solvent systems tested. In a parallel study, impregnation of the adsorbent layer with silver nitrate, aluminium chloride, and boric acid gave unsatisfactory results. Similarly, the use of multiple developing techniques led to unsatisfactory results.

The colour of the individual steroids investigated was characterized by using four different colour reagents (Table 3).

Actually, the $R f$ values of the tested steroids with the different solvent systems used as well as the colours obtained with different colour reagents were thought to be of practical importance for the identification of these compounds if present as transformation mixtures resulting from microbiological transformations of steroids of such structure.

\section{REFERENCES}

1) A. Zaffaroni, R. Burton, and E. H. Kutman, Science, 111, 6 (1950).

2) L. Starka and J. Malikova, J. Endocrinol., 22, 215 (1961).

3) O. Ademc, J. Matis, and M. Galvanek, Lancet, 1, 81 (1962).

4) R. D. Bennet and D. Heftmann, J. Chromatogr., 9, 348 (1962).

5) R. Repole, R. Gasbarro, S. Maglino, and P. Rossi, Rass. Med. Sper., 12, 133 (1965).

6) L. A. R. Sallam, A. H. El-Refai, and N. Naim, J. Gen. Appl. Microbiol., 15, 309 (1969).

7) D. WALdI, In Thin-layer Chromatography, A Laboratory Handbook ed. by E. STAHL, Academic Press, Inc., New York and London (1965) p. 249.

8) D. Heftmann, Chromatography, 2nd ed., Van Nostrand and Reinhold Company, New York and London (1967). 